\title{
An Interdependence Approach to Empathic Concern for Disability and Accessibility: Effects of Gender, Culture, and Priming Self-Construal in Japan and New Zealand
}

\author{
Motohide Miyahara, ${ }^{1}$ Yukinori Sawae, ${ }^{2}$ Rebekah Wilson, ${ }^{1}$ Hahna Briggs,${ }^{1}$ Jiro Ishida, \\ Koichiro Doihata, ${ }^{2}$ and Ayano Sugiyama ${ }^{2}$ \\ ${ }^{1}$ School of Physical Education, Sport and Exercise Sciences, University of Otago, Dunedin, New Zealand \\ 2 Institute of Health and Sport Sciences, University of Tsukuba, Tennodai, Tsukuba, Japan
}

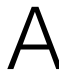
$\mathrm{n}$ interdependence approach to empathic concern could transform the current societal environment for people with disability into a more accessible and equitable one. To our knowledge, this is the first study to investigate two possible factors influencing empathic concern, gender and ethnic culture, in specific helping scenarios. We first examined whether the female gender and collectivist culture of Japan were associated with higher levels of interdependence and empathic concern for disability than were the male gender and individualist culture of New Zealand. Empathic concern for people with impairment was assessed in accessible and inaccessible environments. Neither gender nor culture significantly influenced the level of interdependence, whereas gender and culture differentially moderated empathic concern. We also explored the possibility of altering self-construal and thus promoting prosocial behaviour by examining the correlation between self-construal and prosocial intention, and the effect of cultural priming on self-construal. The correlation was significant under inaccessible conditions in the Japanese sample, and the effect of interdependent priming was not significant on interdependent selfconstrual in both countries. Discussion centres on theoretical implications of the observed conditional support for the female-gender and collectivist-culture hypotheses, and on ways to promote prosocial behaviour, taking into account gender and cultural differences.
\end{abstract}

Keywords: culture, gender, independence, interdependence, prosocial behaviour, individualism, collectivism

Providing an accessible environment for persons of all abilities is an important goal in many societies. However, it is not always possible to provide access to all public environments in ways that meet all needs, and sometimes reliance must be placed on bystanders present to provide support. A recent news report in Japan sheds light on this issue, in which a visually impaired man was hit by a train and killed after he accidently fell on the rail tracks from the platform ('Visually impaired man with guide dog', 2016). To prevent such a tragedy, the installation of platform edge doors was put forward as an urgent priority before the Tokyo Olympic and Paralympic Games take place in 2020 ('Race to install platform doors,' 2017). In addition to the doors, the importance of help from surrounding people on the platform was emphasised by a journalist with visual impairment who himself had had an experience of falling off a train platform ('Blind reporter for The Braille Mainichi', 2016). What kind of bystanders are likely to come to the aid of a person with impairment who is in trouble? Are there any gender differences in helping intentions in Japan? If there are, is the pattern of gender differences consistent between Western and Eastern cultures? Among the myriad factors involved in helping behaviour, we investigated the effects of two potential factors often associated with an interdependence approach to prosocial behaviour (Agnew \& Le, 2015): female gender and collectivist ethnic culture. We also explored the possibility of altering interdependent self-construal in a

Address for correspondence: Motohide Miyahara, School of Physical Education, Exercise and Sport Sciences, University of Otago, POBox 56, Dunedin, New Zealand. Email: motohide.miyahara@otago.ac.nz 
pilot trial to assess the feasibility of encouraging people to act more interdependently, thus potentially increasing prosocial behaviour.

The interdependence approach to prosocial behaviour posits that the extent to which an individual is dependent on interpersonal relationships increases the individual's motivation to act from altruistic motivation rather than from self-interest (Agnew \& Le, 2015). In the context of community participation of people with disability, White, Simpson, Gonda, Ravesloot, and Coble (2010) propose the interdependence model, which stresses the importance of building social capital capacity for people with disability to fully participate in community. An example of the interdependence model is a cooperative interaction between people with and without disability to design accessible public space. Thus, prosociality is influenced by other-orientated empathic concern, or feelings of empathy and concern for others in distress (Williams, O'Driscoll, \& Moore, 2014). The antecedents of empathic concern involve two variables, namely, valuing others' welfare and the perception of others' need, whereas moderating variables associated with empathic concern include female gender, collectivist ethnic culture (Batson, 2011), and interdependent self-construal (Duclos \& Barasch, 2014), that is, the extent to which an individual considers himself or herself connected with others.

Gender differences in empathy and prosocial behaviour have been debated over the past half century of changing gender stereotypes and increasing awareness of the impacts of the stereotypes on measured empathic concern in the United States. Researchers in the 1970s confirmed the prevalent stereotyped beliefs and theorised that girls were socialised to be 'nurturant' across cultures (Whiting \& Edwards, 1973), and that females demonstrated more empathic affect arousal than males, whereas males were set toward instrumental helping action (Hoffman, 1977). In the 1980s, gender differences in empathy and gender-appropriate concern came to be regarded as a mere reflection of self-belief scales on social expectations and desirability (Eisenberg \& Lennon, 1983). Since the 1980s, the female-gender hypothesis of empathic concern has been tested with self-rating questionnaires assessing prosocial behaviour, but the female-gender hypothesis of prosocial behaviour has not been supported in studies conducted in Japan (Nakamura, 1982), New Zealand and Australia (Gilchrist, 2012). In the 1990s in the United States, gender differences were associated with self-construal, in that men were encouraged to develop independent self-construal, while women were supported in fostering interdependent self-construal, with notes on possible variations across ethnic cultures and the prediction that the gender differences may narrow and disappear in the future (Cross \& Madson, 1997). Evidence for gender differences in independent and interdependent selfconstrual in the United States has been equivocal (Foels \& Tomcho, 2009). When the gender hypothesis of empathic concern was tested with objective measures of social (em- pathetic) perspective-taking abilities, no significant gender difference emerged (Tarampi, Heydari, \& Hegarty, 2016). While gender differences in self-construal (Cross \& Madson, 1997) and empathic concern (Batson, 2011) have never been consistently substantiated, the crosscultural variations of gender differences have not yet been explored.

According to Triandis (1989), collectivist cultures foster willingness and capability to empathise with others at cognitive and emotional levels and to altruistically help others' goal achievement. By contrast, individualist cultures drive individuals to think, feel, and act uniquely and distinctively from others. In other words, Easterners have been considered to construe themselves from their social context - that is, to have interdependent self-construal - whereas Westerners have been associated with independent self-construal in that they tend to define themselves in terms of their individual traits (Markus \& Kitayama, 1991). The dual cultural model is supported by a static cross-cultural study that demonstrated that Canadian and Australian university students of European backgrounds rated themselves as engaging in more independent behaviours than did Japanese students (Takemura, Yuki, Kashima, \& Halloran, 2007). Takemura et al. (2007) also compared possible gender differences in self-construal among university students in the Eastern culture of Japan and the Western cultures of Australia and Canada. The researchers found a significant main effect of culture, but the interaction between gender and culture was not significant on interdependence. Their results suggested that gender influence on interdependence is not as strong as cultural influence.

In contrast to Takemura et al.'s (2007) findings, a number of empirical studies failed to support the dual cultural model. According to a review conducted by Takano and Osaka (1999), a possible reason for the lack of support could be attributed to methodological limitations; specifically, questionnaire measurement of self-construal that undermines situational factors. In their attempt to address these limitations, Levine, Norenzayan, and Philbrick (2001) conducted a large cross-cultural study on specific helping behaviours in real-life situations in 23 nations around the world. No clear distinction emerged between individualist and collectivist ethnic cultures, and the study did not examine gender differences. Duclos and Barasch (2014) used fictitious charity scenarios to assess prosocial intentions and found cross-cultural differences, in that collectivists were more willing to help ethnic in-group than out-group members, whereas individualists showed no ethnic preference, possibly because they felt more connected to and inclusive of all others. As in the study by Levine et al. (2001), gender differences were not examined in Duclos and Barasch's (2014) study. To date, no research has investigated the differential roles of gender and culture by employing both self-rating questionnaires and specific situational scenarios to assess interdependence and empathic concern respectively. 
The fact that two methods of assessment have not been used within a study means that the relation between self-construal and helping intention in specific real-life situations has not been examined. If there is a significant correlation between them and if effective ways can be found to foster interdependence behaviour in the general public, this could be a way to increase widespread prosocial behaviour. To explore these possibilities, we investigated the feasibility of changing self-construal by cultural priming, which directs research participants' attention to a specific cultural value (i.e., independence or interdependence). Effects of cultural priming on self-construal have been demonstrated by Chiao et al. (2010) and Duclos and Barasch (2014) in the United States. To date, a dearth of research has examined whether the effects of cultural priming on self-construal vary in distinct cultures.

We seek to fill the above gaps in the literature by first comparing gender and culture effects on self-construal, measured by an explicit self-belief scale, and on empathic concern for disability and accessibility, measured by an experimental task between Japan, as a collectivist culture, and New Zealand, as an individualist culture (Hofstede, 2001). We also test the relation between the level of interdependence and helping intention in Japan and New Zealand. Finally, we test the effect of cultural priming on cultural self-construal in both nations.

Based on the foregoing studies reviewed above, we hypothesised that:

1. The main effect of gender will be insignificant, but the main effect of culture would be significant in that the New Zealanders would be more independent, feel more connected to and inclusive of all others, and willing to help victims of circumstance than the Japanese. No gender and culture interaction effect was expected for either self-construal or helping intention.

2. There will be a significant correlation between cultural self-construal and helping intention in both Japan and New Zealand.

3. There will be a significant effect of interdependent priming on interdependent self-construal in both Japan and New Zealand.

\section{Method}

\section{Participants}

We sampled 129 Japanese (52 males, 77 females) and 104 New Zealand (48 males, 56 females) physical education and sport science major undergraduate students. The Japanese participants were all native Japanese, including a student with long-term physical disability. The ethnic background of the New Zealand participants consisted of 87 participants who identified themselves as New Zealand Europeans, 11 participants as Māori, and one participant as a Pacific Islander. With respect to disability, four New Zealand students had long-term disabilities, encompassing the following domain areas of the New Zealand Census: seeing, walking, hand use, learning, and communication. None of the ethnicity and disability minority students were outliers on the measures described below. Hence, the minority students were grouped together as part of their respective cultural groups, and the participants were grouped only with respect to culture and gender.

\section{Measures}

Cultural self-construal. The cultures of independent and interdependent self-construal were measured with the Cultural Self-Construal Scale (CSCS) developed by Takemura et al. (2007). This 16-item, 7-point Likert scale consists of eight independent and eight interdependent items that were derived from the cultural self-construal scale of Singelis (1994) or Takata, Omoto, and Seike (1996). Both English and Japanese versions are available; the English version has been used in Canada and Australia, and the Japanese version has been used in Japan (Takemura et al., 2007).

Helping intention. To measure prosocial intention in specific situations, we employed a task named the Empathic Concern for Disability and Accessibility (ECDA; Miyahara et al., 2017). The ECDA is an experimental task developed to elicit differential empathic concern between accessible (low-need) and inaccessible (high-need) situations in Japan and New Zealand. This experimental task consists of viewing 60 real-life photos of situations to elicit differential empathic concern between accessible and inaccessible situations. To develop the ECDA we searched for, collected, and took our own photographs of such situations; three experts in adapted physical activity and a former teacher and tour conductor who had worked with people with disabilities searched internet web sites for suitable photographs and written descriptions with English or Japanese search terms, such as a combination of 'disability' and 'inaccessible'. While searching, they consulted with three persons with physical or visual impairment and two disability workers (an occupational therapist and a volunteer worker) for ideas on disabling environments and the content validity of identified photos. This collection was assembled by four research staff members searching, collecting, and taking photographs of such situations, and by consulting with five disability stakeholders. Meaningfulness to university student viewers in both New Zealand and Japan was assessed from qualitative inquiry into disability and accessibility by a panel of three research staff members in New Zealand and three members in Japan. The panel members reached a consensus that: (1) impairments should be limited to impairment in mobility and vision, so that an average university student could understand and imagine the situations easily; (2) a person with impairment should not appear in the photographs, to avoid the confoundings inherent in gender, age, and ethnic group; (3) a person with impairment in mobility or vision should be described in written words such as 'a wheelchair user', or 'a person using a white cane'; (4) the 

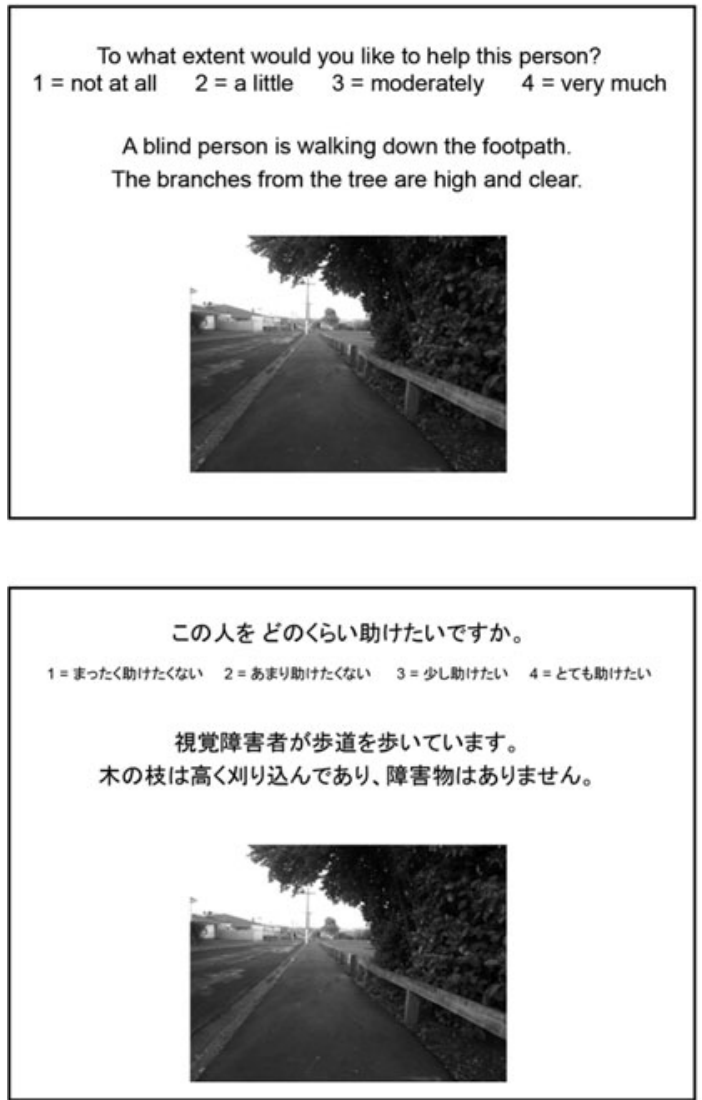

To what extent would you like to help this person? $1=$ not at all $2=$ a little $3=$ moderately $4=$ very much

A blind person is walking down the footpath. The overhanging branches are in the way.
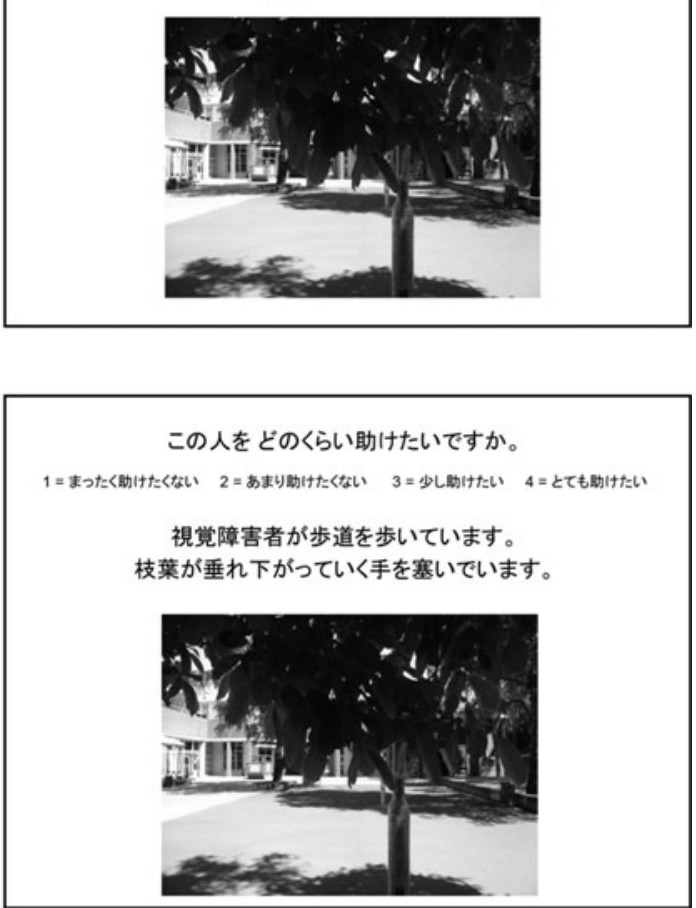

\section{Figure 1}

Examples of Empathic Concern for Disabled People task for accessible (left) and inaccessible (right) conditions.

format of measurement would be a 4-point Likert scale with response anchors of (1) not at all, (2) a little, (3) moderately, and (4) very much, to the question: 'Please watch a series of slides on the screen and circle a number to describe the extent you would like to help the person right after watching each slide'; (5) 30 pairs of accessible and inaccessible conditions in similar places (e.g., a pathway with and without an obstacle), with each slide being displayed for a period of 6 seconds, would be appropriate to answer the question about helping intention on a 4-point Likert scale.

The same photos were used in both Japan and New Zealand, but the verbal descriptions were written in Japanese and English languages in the respective countries. Both Japanese and New Zealand authors made their best efforts to minimise confusion or ambiguity in the photographs and verbal descriptions, so participants could quickly and accurately rate each slide. A verbal description on each photo slide explained the type of impairment (either mobility or visual impairment) and why the person was disabled or not (e.g., overhanging branches were either high and clear or in the way of a blind person walking down the footpath; see Figure 1). After viewing each photo slide with its verbal description, participants were asked how much they wished to help the person described on a slide on the 4-point scale just described. A mean helping intention score from 30 slides of accessible environments, and a mean helping intention score from 30 slides of inaccessible environments were computed for gender and cross-cultural comparisons. The responsiveness of the task scale to change has been demonstrated as an effect of mindfulness meditation (Miyahara et al., 2017). Thus, the content validity and sensitivity to change have been ensured.

Priming task. As an experimental treatment, we employed the Similarities and Differences with Family and Friends (SDFF) task (Trafimow, Triandis, \& Goto 1991). The private self (i.e., independent) priming asked the participants to think for 2 minutes about how different they were from their family and friends and what they wanted to do for their own sake. In contrast, the collective self (i.e., interdependent) priming asked the participants to think for 2 minutes about what they have in common with their family and friends and what was expected from them. A meta-analysis of 10 studies that used this priming task produced an effect size of .49 (Oyserman \& Lee, 2008).

\section{Procedure}

The study was conducted in the context of a large lecture, entitled 'Disability and Assessment' in both Japan 
Table 1.1

Means and Standard Deviations for Independent and Interdependent Self-Construal as a Function of Gender and Ethnic Culture

\begin{tabular}{|c|c|c|c|c|c|c|c|c|}
\hline & \multicolumn{4}{|c|}{ Japan } & \multicolumn{4}{|c|}{ New Zealand } \\
\hline & \multicolumn{2}{|c|}{ Male $(n=50)$} & \multicolumn{2}{|c|}{ Female $(n=71)$} & \multicolumn{2}{|c|}{ Male $(n=47)$} & \multicolumn{2}{|c|}{ Female $(n=56)$} \\
\hline & $M$ & $S D$ & $M$ & $S D$ & $M$ & $S D$ & $M$ & $S D$ \\
\hline \multicolumn{9}{|l|}{ Self-construal } \\
\hline Independent & 4.30 & .98 & 4.37 & .94 & 4.98 & .63 & 4.73 & .82 \\
\hline Interdependent & 4.85 & .80 & 4.80 & .78 & 4.76 & .64 & 4.76 & .84 \\
\hline
\end{tabular}

Table 1.2

Effects of Gender and Culture on Self-Construal

\begin{tabular}{|c|c|c|c|c|c|}
\hline Source & Dependent variable & $d f$ & $F$ & $\eta$ & $p$ \\
\hline \multirow[t]{2}{*}{ Gender } & Independent & 1 & .60 & $<.01$ & .44 \\
\hline & Interdependent & 1 & .08 & $<.01$ & .78 \\
\hline \multirow[t]{2}{*}{ Culture } & Independent & 1 & 19.70 & .08 & $<.01$ \\
\hline & Interdependent & 1 & .35 & $<.01$ & .55 \\
\hline \multirow[t]{2}{*}{ Gender $\times$ culture } & Independent & 1 & 1.73 & $<.01$ & .19 \\
\hline & Interdependent & 1 & .05 & $<.01$ & .82 \\
\hline \multirow[t]{2}{*}{ Error } & Independent & 220 & & & \\
\hline & Interdependent & 220 & & & \\
\hline
\end{tabular}

and New Zealand. After a brief lecture on the topic, the current study was introduced with an explanation of the relevant ethical approval of the study and the right not to participate considerations. A package of survey forms was then distributed to individual students. The anonymous survey form consisted of demographic questions, the ECDA and the pre-priming CSCS, the SDFF priming task (either independent or interdependent), and the post-priming CSCS. The survey forms for independent and interdependent priming tasks appeared to be identi$\mathrm{cal}$, and the forms were alternately ordered in a pile before distributing them during lectures and assigning one of the priming tasks randomly to each student. As part of a learning activity in the lectures, students were asked to view the 60 slides of the ECDA on the screen, and to rate their responses on the survey form.

\section{Results}

\section{Manipulation Check}

To ensure that the accessible and inaccessible stimuli were perceived as low-need and high-need situations, thus eliciting lower and higher degrees of empathic concern and willingness to help respectively in the Japanese and New Zealand samples, we examined the differences in mean ratings on the ECDA task between the accessible and inaccessible conditions with a paired $t$ test. There were significant differences in the willingness to help under the accessible $(M=1.92, S D=.46)$ and inaccessible $(M=$ 3.31, $S D=.53)$ conditions; $t(102)=29.19, p<.01$, in the Japanese sample, and under the accessible $(M=1.71$, $S D=.34)$ and inaccessible $(M=3.48=, S D=.42)$ conditions; $t(120)=43.41, p<.01$, in the New Zealand sample. These significant differences indicated that the accessible and inaccessible stimuli elicited different levels of helping intention in the expected directions in both Japan and New Zealand.

\section{Effects of Gender and Ethnic Culture on Self-Construal in Japan and New Zealand}

To examine whether gender and ethnic culture have different self-construal and whether there was an interaction between gender and culture, we conducted a multivariate analysis of variance (MANOVA). The assumptions of independence of observations and homogeneity of variance and covariance were tested and confirmed, Box's $M=$ $14.18, F(9,403700.56)=1.55, p=.12$. The interaction between gender and culture was not significant, Wilks' $\Lambda=$ 992, $F(2,219)=.871, p=.42$, multivariate $\eta^{2}=.008$. The effect of culture was significant, Wilks' $\Lambda=91, F(2,219)=$ $10.03, p<01$, multivariate $\eta^{2}=.084$. This indicates that the linear composite of self-construal differs for Japan and New Zealand. Follow-up ANOVA (Table 1.1) revealed that ethnic culture effect was significant on independent construal in that the New Zealanders were more independent than the Japanese (See Table 1.2).

\section{Effects of Gender and Ethnic Culture on Helping Intention in Japan and New Zealand}

To examine whether gender and culture have different effects upon helping intention in the accessible and inaccessible conditions, and whether there is an interaction between gender and culture, we conducted a MANOVA. The assumptions of independence of observations and homogeneity of variance and covariance were violated, Box's $M=19.35, F(9,403700.561)=2.004, p=.035$. However, given the large sample, this problem was not regarded 
Table 2.1

Means and Standard Deviations for Empathic Concern for Disability and Accessibility in Accessible and Inaccessible Conditions as a Function of Gender and Ethnic Culture

\begin{tabular}{|c|c|c|c|c|c|c|c|c|}
\hline & \multicolumn{4}{|c|}{ Japan } & \multicolumn{4}{|c|}{ New Zealand } \\
\hline & \multicolumn{2}{|c|}{ Male $(n=50)$} & \multicolumn{2}{|c|}{ Female $(n=71)$} & \multicolumn{2}{|c|}{ Male $(n=47)$} & \multicolumn{2}{|c|}{ Female $(n=56$} \\
\hline & $M$ & $S D$ & $M$ & $S D$ & $M$ & $S D$ & $M$ & $S D$ \\
\hline \multicolumn{9}{|c|}{ Empathic concern for disability and accessibility } \\
\hline Accessible condition & 2.00 & .45 & 1.86 & .47 & 1.63 & .32 & 1.77 & .34 \\
\hline Inaccessible condition & 3.56 & .46 & 3.14 & .50 & 3.34 & .42 & 3.60 & .40 \\
\hline
\end{tabular}

Table 2.2

Effects of Gender and Ethnic Culture on Helping Intention

\begin{tabular}{llrrrr}
\hline Source & Dependent variable & $d f$ & \multicolumn{1}{c}{$F$} & $\eta$ & $p$ \\
\hline Gender & Accessible condition & 1 & $<.01$ & $<.01$ & .98 \\
& Inaccessible condition & 1 & 1.96 & $<.01$ & .16 \\
Culture & Accessible condition & 1 & 17.44 & .07 & $<.01$ \\
& Inaccessible condition & 1 & 4.00 & .02 & $<.05$ \\
Gender $\times$ culture & Accessible condition & 1 & 6.05 & $<.05$ & $<.05$ \\
& Inaccessible condition & 1 & 30.55 & .12 & $<.01$ \\
Error & Accessible condition & 220 & & & \\
& Inaccessible condition & 220 & & & \\
\hline
\end{tabular}

as serious, and we used conservative procedures of Pillai's trace and Type III method for computing the sum of squares. The interaction between gender and culture was significant, Pillai's trace $=.12, F(2,219)=15.22, p<.001$, multivariate $\eta^{2}=.12$. The effect of culture was also significant, Pillai's trace $=.13, F(2,219)=16.94, p<.001$, multivariate $\eta^{2}=.13$. This indicates that the linear composite of helping intention differs for Japan and New Zealand. A follow-up ANOVA (Table 2.2) revealed statistically significant interactions between gender and ethnic culture, and the main effect for ethnic culture on helping intention under both accessible and inaccessible conditions. As Table 2.1 shows, in both accessible and inaccessible conditions the Japanese males expressed a higher level of helping intention than did the Japanese females, whereas the New Zealand males were less willing to help than were the New Zealand females. Further, the Japanese were more willing to help in the accessible condition, whereas the New Zealanders were more willing to help in the inaccessible condition, irrespective of gender.

\section{Self-Construal and Helping Intentions}

Next, we examined whether the extent of independence and interdependence was correlated with helping intentions in the accessible and inaccessible conditions in Japan and New Zealand. As shown in Table 3, significant correlations were found between interdependent self-construal and helping intention under inaccessible conditions only in the Japanese sample.

\section{Effect of Cultural Priming on Cultural Self-Construal}

As Figure 2a shows, the interdependent priming increased interdependent self-construal, but not significantly $(p>.05)$. There was neither significant interaction nor main effect $(p<.05)$ on the subtotal of the interdependent self-construal items of the SCS.

A three-way (culture, priming type, priming) mixed ANOVA revealed a significant interaction, $F(1,226)=$ $8.804, \eta^{2}=.037, p=.003$. The main effect of priming was significant, $F(1,226)=12.763 p<.001$. There was a significant increase of independent self-construal only in the Japanese students after the independent priming $(p<.05)$, and the Japanese students' independent selfconstrual increased to the equivalent level of the New Zealand students (see Figure 2b).

\section{Discussion}

Female gender and collectivist culture have been associated with higher levels of interdependence. The interdependence approach to empathic concern for disability and accessibility posits that a crafted interdependent priming text would strengthen interdependence feelings as a means to increase helping intention. The present study aimed to examine the effects of gender and ethnic culture on self-construal and helping intention in Japan as a collectivist culture, and New Zealand as an individualist culture (Hofstede, 2001). To test the feasibility of strengthening feelings of interdependence as a possible way to increase prosocial behaviour, we examined the relation between self-construal and helping intention, and the effect of cultural priming on self-construal. Support for Hypothesis 1, that no gender difference exists, was mixed and conditional. Consistent with this hypothesis, no gender difference was found on self-construal. With respect to prosocial behaviour the female-gender hypothesis was supported in New Zealand, but not in Japan. 
Table 3

Summary of Intercorrelations Between Self-Construal and Helping Intention in Japan and New Zealand

\begin{tabular}{|c|c|c|c|c|}
\hline & \multicolumn{2}{|c|}{ Interdependence subtotal } & \multicolumn{2}{|c|}{ Independence subtotal } \\
\hline & $r$ & $p$ & $r$ & $p$ \\
\hline \multicolumn{5}{|l|}{ Japan $(n=121)$} \\
\hline Accessible condition subtotal & .07 & .43 & .06 & .54 \\
\hline Inaccessible condition subtotal & 24 & $.01^{* *}$ & -.09 & .33 \\
\hline \multicolumn{5}{|l|}{ New Zealand $(n=103)$} \\
\hline Accessible condition subtotal & .08 & .43 & .06 & .56 \\
\hline Inaccessible condition subtotal & -.13 & .20 & -.01 & .95 \\
\hline
\end{tabular}

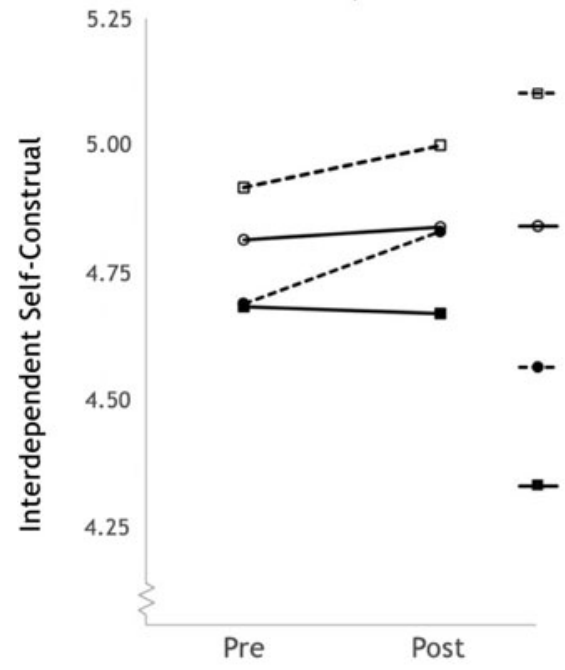

(a)

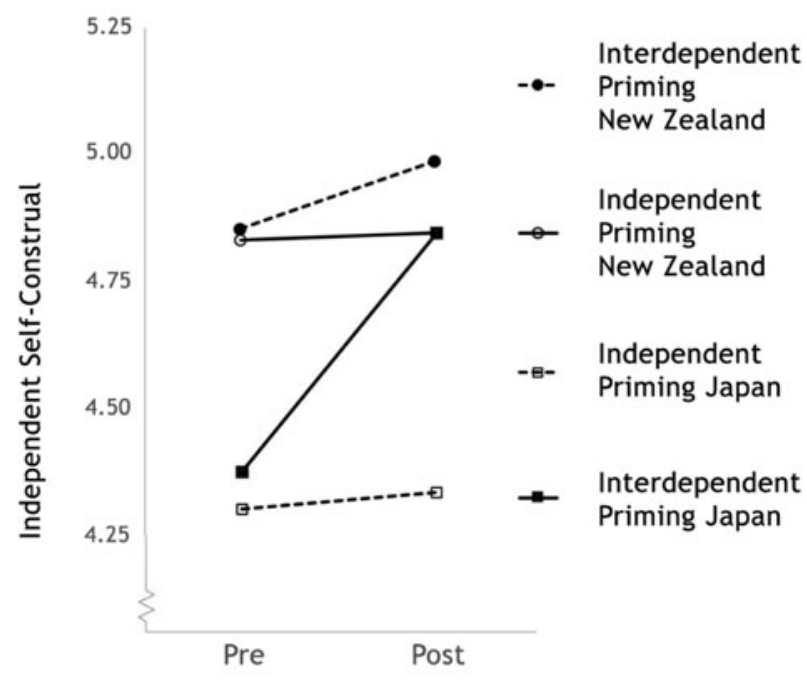

(b)

\section{Figure 2}

Effects of independent and interdependent priming on interdependent (a) and independent (b) self-construal in Japanese and New Zealand students.
Japanese male students expressed a higher level of helping intention than did Japanese female students, whereas New Zealand female students' level of helping intention was higher than that of New Zealand male students, regardless of the helping contexts of accessible and inaccessible environments. Support for hypothesis 2 , that a significant correlation exists between interdependence and empathic concern, was conditional and limited to the Japanese under the inaccessible condition. Hypothesis 3 , that interdependent priming would strengthen interdependent selfbelief, was not supported. A dynamic cultural orientation was not evidenced in interdependent self-construal as an effect of interdependent priming in both Japanese and New Zealand participants. However, a significant increase was observed in independent self-construal as a result of independent priming in the Japanese participants. These findings extend previous findings on the female-gender and collectivist-culture hypothesis and the interdependence approach to prosocial behaviour by demonstrating complex interactions between gender, culture, and the perceived helping need. We will interpret our findings in view of the existing literature.

The female-gender hypothesis of prosocial behaviour was supported in the New Zealand sample, but not in the Japanese sample. Consistent with the social stereotypes in Western cultures whereby women display concern for the socially disadvantaged (Diekman \& Clark, 2015), New Zealand female students were more willing to help people with impairments than were New Zealand male students. On the contrary, for unknown reasons, the Japanese male students were more willing to help people with impairment than were Japanese female students. Such clear gender differences in prosocial behaviours have not previously been found in participants' self-ratings of their general prosocial behaviours in either Japan (Kito, 2002; Nakamura, 1982) or New Zealand (Gilchrist, 2012). The discrepant findings on gender difference in prosocial behaviour between the present study and past studies may be due to our use of specific situations (Takano \& Osaka, 1999), whereas the foregoing studies relied on explicit self-belief scales across the cultures to measure prosocial behaviours (Kitayama, Park, Servincer, \& Karasawa, 2009). Future research can address this question using an equivalent design and measures to test these findings and 
investigate the reasons for the interaction between gender and culture.

The Japanese students' greater willingness to help in accessible compared with inaccessible situations might be explained by the singularity effect proposed by Kogut, Slovic, and Västfjäll (2015), who maintained that the willingness to help a single concrete victim is more pronounced in individualistic cultures than in collectivistic cultures. Kogut et al. (2015) attributed the singularity effect to the perception of a single individual as a more psychologically coherent unit than a group in individualistic cultures, and therefore, the individualists tend to help an individual in need. On the other hand, the collectivists perceive a group as a more coherent unit to act upon, hence the collectivists' hesitation to help an individual. In addition, we would like to provide a further possible interpretation of the singularity effect in terms of the collectivists' reluctance to engage in a solo rescue. When the cost is high to help in the inaccessible conditions, there is a potential barrier to overcome shyness and fear of negative evaluation (Karakashian, Walter, Christopher, \& Lucas, 2006), such as a fear of judgment for not appropriately aiding people with impairment. Among U.S. students, Karakashian et al. (2006) found no significant relation between the fear of negative evaluation and helping behaviour. In collectivist cultures such as Japan, however, we speculate that a significant relation could exist between the fear of negative evaluation and helping behaviour. This hypothesis needs to be tested in future research that sets up helping situations for a single victim and a group of victims.

We observed a significant correlation between interdependent self-construal and prosocial intention only under the inaccessible condition in the Japanese sample. Thus, the interdependence approach to empathic concern for disability and accessibility is applicable to the collectivist sample. In other words, encountering people with impairment being disabled in inaccessible environments, Japanese bystanders may be more willing to help if they have more interdependent self-construal. Although a causal relation should not be inferred from the crosssectional data, in the Japanese sample an increased interdependent self-construal may enhance prosocial intention.

Contrary to Hypothesis 3, the interdependent cultural priming did not significantly increase interdependent self-construal in either Japan or New Zealand, and so did not provide evidence supporting the interdependence approach to prosocial behaviour, using the interdependent priming that we tested. The FDDS task asked participants what they had in common with their family and friends and what was expected from them. A possible limitation of this cultural priming for increasing the interdependent self-construal on the CSCS may lie in the FDDS's narrow focus on family and friends with whom the participants might have different relationships from those with a broader range of 'people around me' and 'my group', which the CSCS targets. This could be a point where the participants might have drawn a line between an ingroup and outgroup for interdependence. In other words, while the FDDS could not create philanthropists, it might foster interdependence only within family and friends, overlooking others in outer circles. Indeed, an interdependent priming increased the collectivists' prosocial behaviour more towards their ethnic ingroup than outgroup, whereas such a group differentiation was not observed in the individualists (Duclos, \& Barasch, 2014). To actualise an interdependence approach to empathic concern for disability and accessibility, an intervention may need to shed a broader light than the FDDS does by extending empathic concern beyond family and friends. Love and kindness (metta) meditation, as part of mindfulness training, is one such intervention that encourages people to love and wish themselves to be well, peaceful, and happy first, then to send the same positive wishes to close families and friends, neutral people, enemies, and infinite beings. The effect of such compassion meditation on the ECDA needs further testing in future studies (Miyahara et al., 2017).

A curious finding of this research was the significant increase in the independent cultural orientation as an effect of independent priming among Japanese students. Provided that the independent and interdependent selfconstruals are orthogonal factors (Singelis, 1994), the orthogonality differs between the two cultures both on and under the surface level, or there is a possible clash between independent and interdependent selves (Markus \& Conner, 2013). The significant effect of independent priming on independent self-construal within the Japanese sample corresponds with a similar effect of independent priming reported in Chinese undergraduate students (Sui, Zhu, \& Chiu, 2007). We replicated the foregoing study and demonstrated that independent priming raised independent self-construal to the same level as the New Zealand students. Thus, our study quantified the hidden dimension of 'psychological differences due to the primed active ingredients of individualism' (Oyserman \& Lee, 2008, p. 313). The unsettled nature of individualism in contemporary Japanese people continues to be debated in the recent literature (e.g., Hamamura, 2012; Ogihara et al., 2015; Ogihara \& Uchida, 2014; Ogihara, Uchida \& Kusumi, 2014). Although our results were not definitive or fully supportive of the hypotheses, they did clarify some other aspects of the model that we argued theoretically and supported with the foregoing empirical studies.

Our study was limited to the samples of undergraduate students majoring in physical education and sport science in Japanese and New Zealand universities. Therefore, we need to interpret and generalise the findings with caution. Given this limitation and the absence of gender and cultural differences in interdependent self-construal, and the lack of a significant interdependent priming effect on interdependent self-construal, future research should focus on the reasons for the differential gender and cultural effects on empathic concern for disability and accessibility, 
as well as how to design gender- and culture-specific disability training, and also examine the effectiveness of the specific training on empathic concern for disability and accessibility.

\section{Acknowledgements}

The authors would like to thank Jackie Hunter for his advice on the procedure of the priming experiment, Tokiko Harada for initial discussion, Jonothan Logan for editorial assistance, and Julie White-Robinson for graphic art.

\section{Declaration of Interest}

There is no known conflict of interest. This study was supported by the School Research Grant, University of Otago.

\section{References}

Agnew, C.R., \& Le, B. (2015). Prosocial behavior in close relationships: An interdependence approach. In D.A. Schroeder \& W.G. Graziano (Eds.), The Oxford handbook of prosocial behavior (pp. 362-375). New York, NY: Oxford University Press.

Batson, D.C. (2011). Altruism in humans. New York, NY: Oxford University Press.

Blind reporter for The Braille Mainichi recalls own experience falling off train platform. (2016b, August 16). The Mainichi. Retrieved from http://mainichi.jp/english/ articles/20160818/p2a/00m/0na/016000c

Chiao, J.Y., Harada, T., Komeda, H., Li, Z., Mano, Y., Saito, D.N., ... Iidaka, T. (2010). Dynamic cultural influences on neural representations of the self. Journal of Cognitive Neuroscience, $22,1-11$.

Cross, S.E., \& Madson, L. (1997). Models of the self: Selfconstruals and gender. Psychological Bulletin, 122, 5-37.

Diekman, A.B., \& Clark, E.K. (2015). Beyond the damsel in distress: Gender differences and similarities in enacting prosocial behavior. In D.A. Schroeder \& W.G. Graziano (Eds.), The Oxford handbook of prosocial behavior (pp. 376-391). New York, NY: Oxford University Press.

Duclos, R., \& Barasch, A. (2014). Prosocial behavior in intergroup relations: How donor self-construal and recipient group-membership shape generosity. Journal of Consumer Research, 41, 93-108.

Eisenberg, N., \& Lennon, R. (1983). Sex differences in empathy and related capacities. Psychological Bulletin, 94(1), 100-131.

Foels, R., \& Tomcho, T.J. (2009). Gender differences in interdependent self-construals: It's not the type of group, it's the way you see it. Self and Identity, 8, 396-417.

Gilchrist, M.E. (2012). Prosocial and antisocial behaviour in ice hockey: The role of the team climate, motivation and moral disengagement (Master's thesis). Retrieved from Otago University Research Archive: https://ourarchive.otago.ac.nz/ handle/10523/2390

Hamamura, T. (2012). Are cultures becoming individualistic? A cross-temporal comparison of individualism-collectivism in the United States and Japan. Personality and Social Psychology Review, 16, 3-24.

Hoffman, M.L. (1977). Sex differences in empathy and related behaviors. Psychological Bulletin, 84, 712-722.

Hofstede, G. (2001). Culture's consequences: Comparing values, behaviors, institutions and organizations across nations. (2nd ed.). Thousand Oaks, CA: Sage.

Karakashian, L, M, Walter, M.I., Christopher, A.N., \& Lucas, T. (2006). Fear of negative evaluation affects helping behavior: The bystander effect revisited. North American Journal of Psychology, 9, 13-32.

Kitayama, S., Park, H., Sevincer, A.T., Karasawa, M., \& Uskul, A.K. (2009). A cultural task analysis of implicit independence: Comparing North America, Western Europe, and East Asia. Journal of Personality and Social Psychology, 97, 236255

Kito, S. (2002). The relation between the quality of helping behavior and personality traits (Unpublished bachelor's thesis). Mukogawa Women's University, Nishinomiya, Hyogo, Japan.

Kogut, T., Slovic, P., \& Västfjäll, D. (2015). Scope insensitivity in helping decisions: Is it a matter of culture and values? Journal of Experimental Psychology, 144, 1042-1052.

Levine, R.V., Norenzayan, A., \& Philbrick, K. (2001). Crosscultural differences in helping strangers. Journal of CrossCultural Psychology, 32, 543-560.

Markus, H.R., \& Conner, A. (2013). Clash!: 8 cultural conflicts that make us who we are. New York, NY: Hudson Street Press.

Markus, H.R. \& Kitayama, S. (1991). Culture and the self: Implications for cognition, emotion, and motivation. Psychological Review, 98, 224-253.

Miyahara, M., Harada, T., Tanaka, S., Fukuhara, H., Kano, T., Ono, T., \& Sadato, N. (2017). Mindfulness meditation for future early childhood teachers in Japan. Teaching and Teacher Education, 65, 136-144.

Nakamura, Y. (1982). Enjokoudou no yokuseiin [Inhibitory determinants of helping behavior: Comparison between a large city and a provincial city]. Tokyo Joshidaigaku Hikakubunnkakennkyuujo Kiyo [Bulletin of Tokyo Women's Christian University, Institute of Comparative Cultures], 43, 65-77.

Ogihara, Y., Fujita, H., Tominaga, H., Ishigaki, S., Kashimoto, T., Takahashi, A., Toyohara, K., \& Uchida, Y. (2015). Are common names becoming less common? The rise in uniqueness and individualism in Japan. Frontiers in Psychology, 6, 1490. doi:10.3389/fpsyg.2015.01490

Ogihara, Y., \& Uchida, Y. (2014). Does individualism bring happiness? Negative effects of individualism on interpersonal relationships and happiness. Frontiers in Psychology, 5, 135. doi:10.3389/fpsyg.2014.00135

Ogihara, Y., Uchida, Y., \& Kusumi, T. (2014). How do Japanese perceive individualism? Examination of the meaning of individualism in Japan. Psychologia, 57, 213-223.

Oyserman, D., \& Lee, S.S.W. (2008). Does culture influence what and how we think? Effects of priming individualism and collectivism. Psychological Bulletin, 134, 311-342. 
Race to install platform doors as need for universal design grows ahead of Olympics. (2017, January 2). The Mainichi. Retrieved from http://mainichi.jp/english/articles/ 20170102/p2a/00m/0na/011000c

Singelis, T.M. (1994). The measurement of independent and interdependent self-construals. Personality and Social Psychology Bulletin, 20, 580-591.

Sui, J., Zhu, Y., \& Chiu, C.-Y. (2007). Bicultural mind, selfconstrual, and self- and mother-reference effects: Consequences of cultural priming on recognition memory. Journal of Experimental Social Psychology, 43, 818-824

Takano, Y., \& Osaka, E. (1999). An unsupported common view: Comparing Japan and the U.S. on individualism/collectivism. Asian Journal of Social Psychology, 2, 311341.

Takata, T., Omoto, M., \& Seike, M. (1996). Sogodokuritsutekisogokyochoteki jikokan shakudo (kaitei ban) no sakusei [Construction of a revised scale for independent and interdependent construal of self]. Nara Daigaku Kiyo [Bulletin of Nara University], 24, 157-173.

Takemura, K., Yuki, M., Kashima, E.S., \& Halloran, M. (2007). A cross-cultural comparison of behaviors and independent/interdependent self-views. In A.B.I. Bernardo, M.C. Gastardo-Conaco, \& M.E.C.D. Liwag (Eds.), The self, relationships, and subjective well-being in Asia: Psychological, social, and cultural perspectives (pp. 105-121). Seoul, Korea: Kyoyook-Kwahak-Sa.
Tarampi, M.R., Heydari, N., \& Hegarty, M. (2016). A tale of two types of perspective taking. Psychological Science, 27, 15071516.

Trafimow, D., Triandis, H., \& Goto, S.G. (1991). Some tests of the distinction between the private self and the collective self. Journal of Personality and Social Psychology, 60, 649655.

Triandis, H.C. (1989). The self and social behavior in differing cultural contexts. Psychological Review, 96, 506520.

Visually impaired man with guide dog fatally struck by train after fall from platform in Tokyo. (2016, August 16). The Mainichi. Retrieved from http://mainichi.jp/ english/articles/20160816/p2a/00m/0na/005000c

White, G.W., Simpson, J.L., Gonda, C., Ravesloot, C., \& Coble, Z. (2010). Moving from independence to interdependence: A conceptual model for better understanding community participation centers for independent living consumers. Journal of Disability Policy Studies, 20, 233240.

Whiting, B., \& Edwards, C.P. (1973). A cross-cultural analysis of sex differences in the behavior of children aged 3 to 11 . Journal of Social Psychology, 91, 171-188.

Williams, A., O’Driscoll, K., \& Moore, C. (2014). The influence of empathic concern on prosocial behavior in children. Frontiers in Psychology, 5, 425. 